\title{
APPROPRIATE KNOWLEDGES: AN EXPLORATION OF SOUTH AFRICAN INDUSTRIAL DESIGN CURRICULA IN THE ERA OF 4IR
}

\author{
Oluwafemi S. ADELABU and Angus D. CAMPBELL \\ Department of Industrial Design, University of Johannesburg, South Africa
}

\begin{abstract}
Since the era of the first industrial revolution, design has played a significant role in bringing about social-economic transformation through technology and yet it still holds great potential to encourage human flourishing in the future. However, as the making of things is getting smarter, a higher level of critical design thinking will be required to fulfil human needs more sustainably. The Fourth Industrial Revolution (4IR) has been proposed as a new frontier and South African educational institutions have been charged to develop content to meet the needs of learners for this new era. This paper documents a study that explored the curricula of Industrial Design programmes offered in four South African Higher Education institutions. The study employed a literature review and thematic analysis as exploratory methods for unbundling the 4IR components of these programmes. The findings documented to what extent these curricula had been designed to sufficiently prepare graduates for the future world of work in the highly unequal South African context.
\end{abstract}

Keywords: Industrial design education, curriculum, appropriate knowledges, 4IR, design for sustainability

\section{INTRODUCTION}

Design at its root cannot be separated from human development - even in the Palaeolithic period, toolmaking was key to successful hunting and wild harvesting. However, the role of design as a discipline playing an active role in the human civilization project is far more prominent from the First Industrial Revolution, where it played a key role in marketing the outcomes of mechanised production that harnessed water and steam technology, bringing about significant societal transformations [1]. The Second Industrial Revolution continued the focus on production through electric power, and again design played a key role in promoting consumption. The Third Industrial Revolution was the use of electronics and Information Communication Technologies (ICT) to automate production and integrate such technologies into products. This went hand-in-hand with the development of new design disciplines such as Interaction Design. This leads into the contemporary Fourth Industrial Revolution (4IR), characterised by the fusion of digital, biological and physical innovations - which potentially can impact all disciplines, economies and industries [2], [3].

In the 4IR, there is a clear need for restructuring higher education curricula to deliver skills and knowledge most needed by graduates for successful contribution in the new world of work [4]. This study recognises the growing concerns for the future of design education especially as seen in a wide range of recent explorations by several communities of design educators and practitioners [5]-[7]. Thus far, not much has been done to specifically probe Industrial Design (ID) curricula, particularly in the Global South where 4IR could have a significant impact. The aim of this study, therefore, was to explore the content and concept of ID curricula in South African Higher Education institutions. The specific research questions raised for the study were:

1. What are the prominent attributes of ID education in South Africa?

2. What are the social, technological and ecological components of ID curricula in South African Higher Education?

3. What are likely implications for curricular development in the 4IR era?

It is hoped that the outcome of this study will guide future reviews of design programmes and also contribute to effective policy formulation hinged on a proper implementation of effective curriculum 
and educational practices, which are appropriately tailored toward meeting societal, technological and ecological needs in the 4IR era.

\subsection{Rationale for the study}

Design education is of great value to creative education in that it helps to nurture design talents for the socio-cultural and economic development of society. As the world experiences rapid advancement in science and technology, it becomes crucial to constantly question the timeliness of knowledge and skills and their relevance to solving emerging challenges across the spectrum of human development and ecological sustainability.

\section{METHODOLOGY}

The study took an exploratory approach to understand the curricular structure of ID programmes in South African higher institutions. A review of relevant literature was undertaken on the development of ID education and the imperative of 4IR in South Africa. Data were collected from publicly available sources on ID curricula currently operational in the four institutions offering ID programmes. A thematic analysis [8], [9] of curricular text data was carried out to deconstruct the curricular content of the programmes as approved by the South African Qualifications Authority (SAQA). A qualitative analysis software - Quirkos was adopted as a qualitative data analysis software (QDAS) tool [10] to identify, establish and analyse patterns of themes in the text data. The study was delimited in term of the depth of information available about the programme curricula.

\section{FINDINGS AND DISCUSSION}

Based on the analysis of data drawn from the programme curricula and relevant literature, the study documents and discusses key findings on the dominant attributes of ID education in South Africa. This includes the social, technological and ecological components of the current curricula and their implications for 4IR-ready design education in a South African context.

Table 1. South African Universities offering ID and closely related programme

\begin{tabular}{|c|c|c|c|c|c|}
\hline $\mathbf{S} / \mathbf{N}$ & & Institution & Faculty & $\begin{array}{l}\text { Undergraduate Degree } \\
\text { programmes in ID }\end{array}$ & Duration \\
\hline 1. & \multirow{3}{*}{ 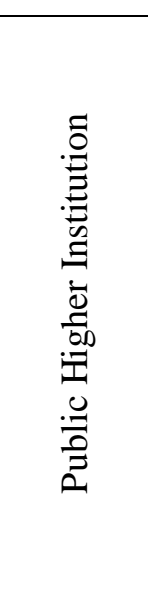 } & $\begin{array}{l}\text { University of } \\
\text { Johannesburg } \\
\text { (UJ) }\end{array}$ & $\begin{array}{l}\text { Arts, Design and } \\
\text { Architecture }\end{array}$ & $\begin{array}{l}\text { B.A. } \\
\text { Industrial Design } \\
\text { B.A. Honours } \\
\text { Industrial Design }\end{array}$ & $\begin{array}{l}3 \text { years } \\
1 \text { year }\end{array}$ \\
\hline 2. & & $\begin{array}{l}\text { Cape Peninsula } \\
\text { University of } \\
\text { Technology } \\
\text { (CPUT) }\end{array}$ & $\begin{array}{l}\text { Informatics and } \\
\text { Design }\end{array}$ & $\begin{array}{l}\text { Diploma in Industrial } \\
\text { Design } \\
\text { Adv. Diploma in } \\
\text { Industrial Design }\end{array}$ & $\begin{array}{l}3 \text { years } \\
1 \text { year }\end{array}$ \\
\hline 3. & & $\begin{array}{l}\text { Tshwane } \\
\text { University of } \\
\text { Science and } \\
\text { Technology } \\
\text { (TUT) }\end{array}$ & $\begin{array}{l}\text { Engineering and the } \\
\text { Built Environment }\end{array}$ & $\begin{array}{l}\text { Diploma in Industrial } \\
\text { Design } \\
\text { Adv. Diploma in } \\
\text { Industrial Design }\end{array}$ & $\begin{array}{l}3 \text { years } \\
1 \text { year }\end{array}$ \\
\hline 4. & 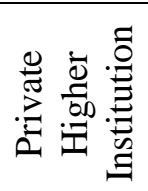 & $\begin{array}{l}\text { Open Window } \\
\text { Institute }\end{array}$ & $\begin{array}{l}\text { School of Creative } \\
\text { Technologies }\end{array}$ & $\begin{array}{l}\text { B.A. Interaction Design } \\
\text { (3D Design) }\end{array}$ & 3 years \\
\hline
\end{tabular}

\subsection{ID education in South Africa}

The pioneering tertiary programme in ID in South Africa was introduced in 1963 at the School of Art Johannesburg [11]. It became the Technikon Witwatersrand (TWR) in 1979 and then the University of Johannesburg (UJ) in 2005 when it was merged with Rand Afrikaans University (RAU) [12]. A notable proponent and founder of the programme was Phil Botha, a graduate of the Central School of Art in London in the late 1950s [13]. An additional three programmes in ID were later established at the Cape Technikon in 1988 (now Cape Peninsula University of Technology - CPUT), Tshwane University of 
Technology (TUT) in 2008 and at Open Window institute not earlier than 2011. In terms of curricular development, the ID programmes run in the public institutions share many similarities because the TWR (now UJ) and CT (now CPUT) evolved together as technikons whilst a graduate of the TWR started the ID programme in TUT. Campbell [13] noted that at the onset of the TWR ID programme, the model for ID education in SA was framed on the British Industrial Arts model. Botha, the pioneer of the programme was greatly influenced by his design education underpinned with the philosophy of "good design," promoted by the Council of Industrial Design (CoID) in the UK from 1944. Due to the segregation of South African society by the apartheid regime, the programme was dominated by white men with a curriculum of Eurocentric content and approaches to design. Following the abolishment of the apartheid system in 1994, South African ID programmes began to redirect their focus to suit the design needs of the local context slowly embracing the diversity of South African society.

\subsection{The Fourth Industrial Revolution and South African imperatives}

The 4IR has become a global phenomenon associated with a remarkable shift in manufacturing and production technology that breeds a new culture of work systems with attendant social-economic effect. The 4IR can be described as the "result of an integration and compounding effects of multiple exponential technologies, such as artificial intelligence (AI), biotechnologies and nanomaterials" [4]. The drive for assimilating the technologies of 4IR and the imperative of acquiring 21st'century skills is challenging the state of the educational system globally. South Africa has started to deliberately align itself with the realities and expectation of an era where much of the work that exists today will no longer be in demand. The initiatives to integrate 4IR better into South African society are manifested through multi-level partnerships aimed at the formation of policies, plans and strategies. Some of these include the Presidential Commission on 4IR [14], the Agenda for the 4IR in South Africa (4IRSA Partnership) [15] and the Ministerial Task Team on the 4IR in Post-school Education and Training [16]. The government is, therefore, considering how to adjust the education system to meet the competency needs of a smart society across school levels.

\subsection{Prominent Attributes of ID Higher Education in South Africa}

Four institutions of higher learning are currently offering ID programmes (Table 1). These comprise of three out of the 26 public universities in South Africa and one private institute of design which offers the programme as 3D Design in Interaction Design. From the data which were subjected to qualitative analysis, a pattern of three layers of interconnected over-arching themes was established around the core of ID education in South Africa. The three layers are found to be predominantly rooted in the notion of "appropriate knowledges" which are guided to produce results for "relevant and context-based" outcomes. Overall, this curricular framework suggests an integrated model of learning and skillacquisition for citizenship building. The themes at the inner layer or foundation stage indicate a pattern of learning which strives to expose the students to fundamentals of design covering basic design knowledge, skills and competency building and exploration of materials, tools and technology. Following this is the mid-layer/intermediate stage which advances students into design practice guided by research/academic literacies, exploration of the design process and design for outcomes. The outer layer builds on the former with a level of awareness for social, economic and environmental considerations. From the inside out, this model tends to suggest a curriculum landscape where a formative evaluation of student learning is employed at the beginning and shifted progressively to a summative evaluation approach towards the end. Traditionally, ID education is rooted in studio-based learning, which allows for knowledge building and creative problem solving synthesizing skills with technology and learn by "doing" [17]. As the students get to build a fundamental skill set and competency in the making of things, they move on to "meaning-making" [18] using critical design thinking and communication skills as the design process becomes more important.

Overall, the dominant underlying elements of 'appropriate' knowledge application for context-based and relevant design outcomes emphasize the notion of building 'critical citizenship' through design education in South Africa. Notably, education for citizenship building is being re-defined and explored as a model of design teaching and learning pedagogies across different fields of design in the postapartheid context [19]. The ID Department at UJ exemplifies this concept through projects which allow student designers to apply their design knowledge and expertise in driving appropriate change in broader society (for examples, see [20] and [21]). This orientation of education, which hovers around the concept of design for social responsibility [22], [23], essentially aims to promote "a critical mind-set, 
methodologies, tools and skills for appropriate change-making embedded in complex contexts" [21]. This study infers that the ID curricula across the schools show integration of research-led design practice fostered by appropriate design knowledges, competencies and skills for the development of design solutions with social, technical, economic and environmental considerations (as illustrated in Figure 1).

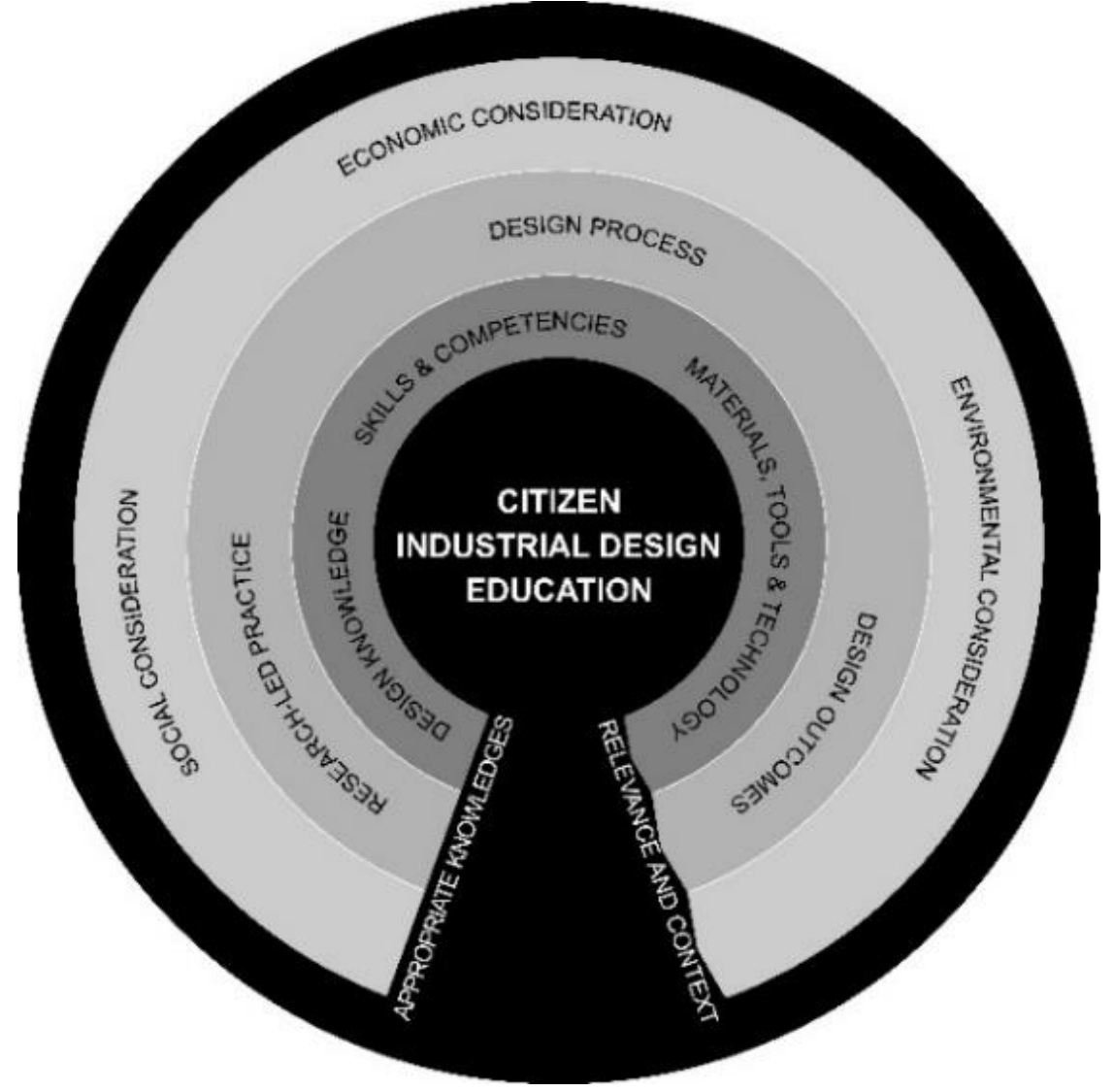

Figure 1. A framework showing the underlying concepts for ID education in South Africa

\subsection{The Social, Technological and Ecological Components in the ID curriculum in South African Higher Education}

Following the result of the thematic analysis, social, technological and ecological considerations were found to be key components of the existing curricula, though at varying levels. Emphasis was placed on the need to consider appropriate technological applications in solving design problems with an understanding of users' social context. This included consideration for global markets, systems and cultures. Consideration for ecological sustainability in the design process was relatively low across the body of curricular texts. The technological aspect of curricula content included consideration for tools, emerging technologies and industrial processes. The integration of modules reflecting 4IR technologies was mostly evident in the 3D Design programme curriculum offered at the Open Window Institute; with training including a wider range of 4IR technologies such as the Internet of Things (IoT), wearable technology, smart object design and other interdisciplinary modules such as physical computing. Based on the available data, it appeared that the level of integration of new technologies is not well reflected in the curricular content of the ID programmes offered in the public higher institutions. However, it is also noted that these curricula are older and are written to broadly allow for relevant context to be integrated as is needed. Therefore, deeper one-on-one investigation with those that offer the programmes will be required to unpack this further. With the current drive of the government through the Presidential Commission on the 4IR, it is expected that consideration for integrating new 4IR technologies will become a priority. For student designers to stay competitive in a diverse and creative economy, curricular content must be responsive to continuously adopt new and emerging technologies for the training of future designers. 


\subsection{Imperative of Curricular Development for the 4IR Era}

A recent definition of ID given by the World Design Organisation [24] in 2015 established ID as a transdisciplinary profession that offers creative and problem-solving potentials and tools to "provide new value and competitive advantage across economic, social, and environmental spheres". Nevertheless, ID education is shaped by the way it is taught, which determines whether designers being trained are capable of dealing with the complexities of design problems [22], the demands of the future workplace, and the emerging systems of manufacture. Hence, there is a need for ID education curricula in the 4IR to be oriented towards providing learners with appropriate knowledges and competencies towards such ends.

While the 4IR era proposes a future filled with possibilities yet uncovered [25], its assimilation within the higher education curricular framework must go beyond its technological and economic aspects to also consider social, cultural, and ecological relevance [26]. This will enable society to critically map the implications of 4IR on sustainable development and to effect positive transformation on existing challenges such as inequality, unemployment, demographic changes and other stubborn realities that are faced with South Africa and many other developing economies. A broader assessment of the current ID programmes in South Africa indicates that wide areas required for all-round training of critical citizen designers are reflected in the curriculum. While this study has not closely examined other factors affecting curriculum content delivery, the result from the thematic analysis shows that the weight attributed to various aspects of the curricula varies. This will need reconsideration given what is relevant and needs to be taught to equip learners with appropriate knowledges for the 4IR era. While the vision of developing a critical citizenship design education is reflected in the current curricula, the untapped potentials for achieving an optimal learning outcome must be developed further. There would be needs to consider the integration of essential lifelong learning skills that will enable learners to rise dynamically to the challenges of the 4IR era in creating multiple and sustainable design outcomes [23], [27]. Innovative pedagogies that promote adaptability, flexibility, and human engagement skills will also give students the edge as traditional roles become increasingly automated.

\section{CONCLUDING REMARKS}

This study has attempted to explore the content and concept of ID curricula in South African Higher Education using publicly available data. Hopefully, this will lay a groundwork for future studies and provide useful hints for developing effective ID curricular frameworks in the 4IR era. With the drive for new skills development and integration in South African higher education, the responsibility of providing the emerging generation of designers with the right sets of tools, knowledges and values for maintaining a systemic balance in the social, technical and ecological system is imperative.

\section{ACKNOWLEDGEMENT}

The authors wish to acknowledge the Global Excellence Stature (GES) 4.0 Funding for Postdoctoral Research for providing the support necessary to conduct this research.

\section{REFERENCES}

[1] Baynes K. and Baynes B. Models of Change: The Future of Design Education. Design and Technology Education: An International Journal, 2010, 15(3), 10-17.

[2] Schwab K. The Fourth Industrial Revolution, 2017 (Penguin Books Limited, London).

[3] Schwab K. The Fourth Industrial Revolution. Encyclopædia Britannica, Inc. Available: https://www.britannica.com/topic/The-Fourth-Industrial-Revolution-2119734 [Accessed on 2020, 15 February], (2018) May 25.

[4] Penprase B.E. The Fourth Industrial Revolution and Higher Education. In Gleason N.W. (ed.), Higher Education in the Era of the Fourth Industrial Revolution, 2018, pp.207-228.

[5] Spitz, R. Die Zukunft der Designlehre/The Future of Design Education: 4. Hearing der iF Design Foundation in Johannesburg. Available: https://renespitz.de/2020/01/20/die-zukunftder-designlehre-the-future-of-design-education-4-hearing-der-if-design-foundation-injohannesburg/ [Accessed on 2020, 15 February], (2020) 20 January.

[6] Design Educators Forum of Southern Africa. Designed Futures: Design educators interrogating the future of design knowledge, research and education. Available: https://www.defsa.org.za/2019-international-defsa [Accessed on 2020, 15 February], (2019).

[7] Globally We Design. ReDesignEd Educators Forum 2019: What We Don't or Can't Teach: 
Bridging the Knowledge Gap. Available: https://www.globallywedesign.com/2019-educatorsforum [Accessed on 2020, 15 February], (2019).

[8] Braun V. and Clarke V. Using thematic analysis in psychology. Qualitative Research in Psychology, 2006, 3(2), 77-101.

[9] Gibbs G.R. Analysing qualitative data, 2007 (SAGE, London).

[10] Gilbert L.S., Jackson K. and di Gregorio S. Tools for analysing qualitative data: The history and relevance of qualitative data analysis software. In Spector J., Merrill M., Elen J., and Bishop M. (eds), Handbook of Research on Educational Communications and Technology, 2014, pp.221236 (Springer, New York, NY).

[11] Wood V.C. Industrial Design. Lantern - Journal of Knowledge and Culture, 1963, 12(4), 34-63.

[12] Brink E. FADA: A history 1926-2006, 2006 (University of Johannesburg, Johannesburg).

[13] Campbell A.D. Industrial Design Education and South African Imperatives. Image \& Text: A Journal for Design, 14, 2008, 82-99.

[14] Department of Telecommunications and Postal Services. Terms of Reference for the Presidential Commission on the Fourth Industrial Revolution. Government Gazette, 2019, 4(42388). Available:

https://www.gov.za/sites/default/files/gcis_document/201904/42388gen209.pdf [Accessed on 2020, 15 February].

[15] 4IRSA. Stimulating Dialogue, Insight and Action to Shape a 4IR Response for South Africa. Available: https://4irsa.org/storage/2019/04/4IRSA-2019.pdf [Accessed on 2020, 15 February], (2019).

[16] Department of Higher Education and Training. Ministerial Task Team on the Fourth Industrial Revolution in Post-School Education and Training. Government Gazette, 2019, 4(42518). Available: https://www.gov.za/sites/default/files/gcis_document/201906/42518gon893.pdf [Accessed on 2020, 15 February].

[17] Schön D. A. The Design Studio: an Exploration of its Traditions and Potentials, 1985 (RIBA Publications for the RIBA Building Trust, London).

[18] Kazmierczak E.T. Design as meaning making: from making things to the design of thinking. Design Issues, 2003, 19(2), 45-59.

[19] Costandius E. and Botes H. eds. Educating Citizen Designers in South Africa, 2018 (AFRICAN SUN MeDIA, Cape Town, South Africa).

[20] Campbell A.D. and Harrison P.H. A framework for socio-technical innovation: the case of a human-powered shredder. In Cumulus Conference, Milan, June 2015, pp.211-230.

[21] Campbell A. D. and Brown I. L. A potential difference model for educating critical citizen designers: The case study of the Beegin appropriate technology beekeeping system. In Costandius E. and Botes H. (eds), Educating Citizen Designers in South Africa, 2018, pp.85-104 (AFRICAN SUN MeDIA, Cape Town, South Africa).

[22] Manzini E. Small, local, open and connected: Design for social innovation and sustainability. Journal of Design Strategies, 2010, 4(1), 8-11.

[23] Ceschin F. \& Gaziulusoy I. Design for sustainability: A multi-level framework from products to socio-technical systems, 2020 (Routledge, Abingdon, Oxon).

[24] WDO. Definition of Industrial Design. https://wdo.org/about/definition/ [Accessed on 2020, 15 February], (2015).

[25] PwC and WEF. Innovation for the Earth: Harnessing technological breakthroughs for people and the planet. Available: https://www.pwc.com/ee/et/publications/pub/innovation-for-theearth.pdf [Accessed on 2020, 15 February], (2017).

[26] Pfeiffer S. The Vision of Industry 4.0 in the Making - a Case of Future Told, Tamed, and Traded. Nanoethics, 2017, 11, 107-121.

[27] Dunne A. and Raby F. Speculative everything: Design, fiction and social dreaming, 2013 (The MIT Press, Cambridge, MA). 